\title{
A study on the effect of teleworking on quality of work life
}

\author{
Amir Azarbouyeh $^{a^{*}}$ and Seyed Gholamreza Jalali Naini ${ }^{b}$
}

${ }^{a}$ Department of Industrial Engineering, Iran University of Science and Technology, Tehran, Iran ${ }^{b}$ Department of Industrial Engineering, Iran University of Science and Technology, Tehran, Iran

\section{H R O N I C L E}

Article history:

Received December 2, 2013

Accepted February 20, 2014

Available online

May 212014

Keywords:

Teleworking

Quality of Working-Life

Productivity \begin{abstract}
A B S T R A C T
Nowadays teleworking has become a useful technique for business development and improving employees' quality of life. Many people are now able to stay at home and do their daily job activities without bothering to wear formal closes. This paper presents an empirical investigation to study the effect of teleworking on quality of life using Walton (1976) method [Walton, R. E. (1973). Quality of working life-what is it. Sloan Management Review, 15(1), 1121.]. The variables of quality of working-life according to Walton Model are: "Adequate and fair compensation", "Safe and Healthy Working conditions", "Opportunity for Continued Growth and Security", "The Social Relevance of Work Life", "Total Life Space", "Social Integration in the Work", "Constitutionalism in the work Organization", "Human Progress Capabilities". Using different statistical tests, the study indicate that teleworking had significant positive relationship with Quality of Working-Life components. The study also reports that different personal characteristics such as age, gender had no meaningful impact on teleworking.
\end{abstract}

(C) 2014 Growing Science Ltd. All rights reserved.

\section{Introduction}

Teleworking has become one of the most popular methods for saving employees' time and energy and there are various studies on learning more about the effects of teleworking on quality of life (Illegems et al., 2001; Siha \& Monroe, 2006; Wellman \& Haythornthwaite, 2008). Baruch (2000), for instance, explored how teleworking was perceived by employees and highlighted its possible advantage and pitfalls. The study investigated teleworking effect on effectiveness, quality of working life, and family life. Bailey and Kurland (2002) looked to find appropriate responses to different questions such as who take part in telework, why they do, and what occurs when they do. They reported that little clear evidence were available that telework could increase job satisfaction and productivity, as it is often asserted to do. They recommended three steps for future research could provide richer insights including consider group and organizational level effects to understand whom telework influences, reconsidered why people telework, and emphasize theory-building and links to

*Corresponding author. Tel: +989122141227

E-mail addresses: amir azarbouyeh@ind.iust.ac.ir (A. Azarbouyeh) 
existing organizational theories. They concluded with lessons learned from the telework literature that could be relevant to research on new work forms and workplaces.

Fonner and Roloff (2010) challenged assumptions regarding the value and necessity of frequent faceto-face workplace interaction by building upon a theoretical framework for the consequences of telecommuting. The reported that high-intensity teleworkers were more satisfied than office-based employees and reached substantial advantages from their work arrangement, with work-life conflict most influential toward job satisfaction. Taskin (2010) introduced telework in a public and bureaucratic environment and argued that the adoption of such organizational change depends on the ability to re-negotiate the prevailing organizational conventions.

\section{The proposed study}

The study undertaken explored the relationship between Teleworking and Quality of Working-Life. The main hypothesis of the survey is as follows,

Main hypothesis: There is a meaningful and positive relationship between teleworking and quality of working-life.

The study also considers the following eight sub-hypotheses,

1. There is a meaningful and positive relationship between teleworking and adequate and fair compensation.

2. There is a meaningful and positive relationship between teleworking and safe and healthy working conditions.

3. There is meaningful and positive relationship between teleworking and opportunity for continued growth and security.

4. There is meaningful and positive relationship between teleworking and the social relevance of work life.

5. There is meaningful and positive relationship between teleworking and total life space.

6. There is meaningful and positive relationship between teleworking and social integration in the work.

7. There is meaningful and positive relationship between teleworking and constitutionalism in the work organization.

8. There is meaningful and positive relationship between teleworking and social integration in the work.

The proposed study has been accomplished among people who worked for one of Iranian knowledge based organizations. The sample size is calculated as follows,

$$
n=\frac{N \times z_{\alpha / 2}^{2} \times p \times q}{\varepsilon^{2} \times(N-1)+z_{\alpha / 2}^{2} \times p \times q},
$$


where $N$ is the population size, $p=1-q$ represents the yes/no categories, $z_{\alpha / 2}$ is CDF of normal distribution and finally $\varepsilon$ is the error term. Since we have $p=0.5, z_{\alpha / 2}=1.96$ and $N=190$, the number of sample size is calculated as $n=105$. The study distributed 135 questionnaires and managed to collect 111 properly filled ones. All questions were designed in Likert scale and using a sample of 30 people, the validity of the questionnaire was evaluated. Cronbach alpha for the overal question was calculated as 0.845 and all eight hypotheses including "Adequate and fair compensation", "Safe and Healthy Working conditions", "Opportunity for Continued Growth and Security", "The Social Relevance of Work Life", "Total Life Space", "Social Integration in the Work", "Constitutionalism in the work Organization" and "Human Progress Capabilities" were caluclated as 0.845, 0.634, 0.777, $0.867,0.822,0.838,0.834,0.889$ and 0.766 , respectively. Fig. 1 shows details of personal characteristics of the participants.

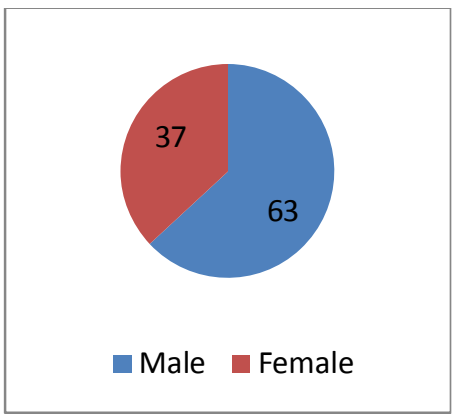

Gender

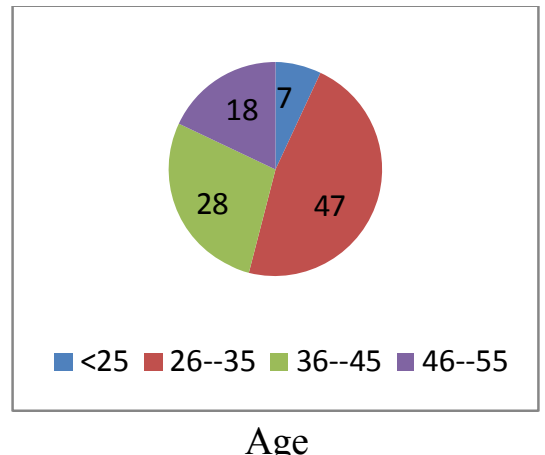

Age

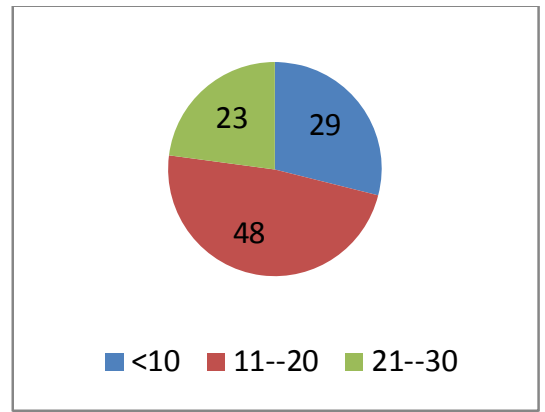

Years of job experiences

Fig. 1. Personal characteristics of the participants

As we can observe from the results of Fig.1, most participants who took part in our survey were male and they were middle-aged people and highly educated. In addition, $29 \%$ of the participants were managers and the rest of $71 \%$ were regular employees. Table 1 shows some basic statistics associated with different components of the survey.

\section{Table 1}

The summary of some basic statistics

\begin{tabular}{lcc}
\hline Variable & Mean & Standard deviation \\
\hline Adequate and fair compensation & 3.6757 & 0.97697 \\
Safe and healthy working conditions & 4.0293 & 1.01452 \\
Opportunity for continued growth and security & 2.6366 & 0.70825 \\
The social relevance of work life & 3.8498 & 0.89892 \\
Total life space & 4.1171 & 0.7183 \\
Social integration in the work & 2.8078 & 0.86287 \\
Constitutionalism in the work organization & 3.3333 & 0.74898 \\
Social integration in the work & 4.5676 & 0.38285 \\
\hline
\end{tabular}

As we can observe from the results of Table 1, Social integration in the work, Total life space and safe and healthy working conditions have received the highest scores while Opportunity for continued growth and security has received the minimum score. The proposed study of this paper has applied structural equation modeling to examine difference hypotheses of the survey.

\section{The results}

The implementation of structural equation modeling has been accomplished by using LISREL software package. The results of Chi-Square/df $=1.44$, RMSEA $=0.063$, AGFI $=0.86$, GFI $=0.91$ and NFI $=0.95$. These values are well above the desirable limits. In addition, all sub-hypotheses have been confirmed and we could conclude that teleworking influences positively on all mentioned 
factors on sub-hypothesis 1 to sub-hypothesis 8 . We have also performed t-test to verify all subhypotheses of the survey and Table 3 demonstrates the results of our findings.

Table 3

The results of t-test on examining eight sub-hypotheses of the survey

\begin{tabular}{lcccc}
\hline Variable & Mean & t-value & Sig. & Result \\
\hline Adequate and fair compensation & 3.6757 & 7.287 & 0.000 & $\sqrt{ }$ \\
Safe and healthy working conditions & 4.0293 & 10.689 & 0.000 & $\sqrt{ }$ \\
Opportunity for continued growth and security & 2.6366 & -5.405 & 0.000 & $\sqrt{ }$ \\
The social relevance of work life & 3.8498 & 9.961 & 0.000 & $\sqrt{ }$ \\
Total life space & 4.1171 & 16.385 & 0.000 & $\sqrt{ }$ \\
Social integration in the work & 2.8078 & -2.347 & 0.021 & $\sqrt{ }$ \\
Constitutionalism in the work organization & 3.3333 & 4.689 & 0.000 & $\sqrt{ }$ \\
Social integration in the work & 4.5676 & 43.138 & 0.000 & $\sqrt{ }$ \\
\hline
\end{tabular}

The results of Table 3 confirm that teleworking influences on quality of work life when the level of significance is five percent and in order to rank these factors, we have used Freedman test, which are summarized in Table 4 as follows,

\section{Table 4}

The results of Freedman test

\begin{tabular}{lc}
\hline Variable & Freedman statistic \\
\hline Adequate and fair compensation & 4.68 \\
Safe and healthy working conditions & 5.53 \\
Opportunity for continued growth and security & 2.19 \\
The social relevance of work life & 5.00 \\
Total life space & 2.68 \\
Social integration in the work & 2.8078 \\
Constitutionalism in the work organization & 3.59 \\
Social integration in the work & 6.66 \\
\hline
\end{tabular}

Next, we present details of our findings on the effects of personal characteristics on teleworking.

\subsection{The effect of gender}

We use t-student test to verify the effect of gender on mean difference of two groups and Table 4 demonstrates the results of our survey.

\section{Table 4}

The results of gender on mean difference on telemarketing

\begin{tabular}{lccc}
\hline Variable & Male & Female & Sig. \\
\hline Adequate and fair compensation & 3.8667 & 3.3496 & 0.130 \\
Safe and healthy working conditions & 4.0964 & 3.9146 & 0.365 \\
Opportunity for continued growth and & 2.6190 & 2.6667 & 0.734 \\
The social relevance of work life & 3.9643 & 3.6545 & 0.080 \\
Total life space & 4.1214 & 4.1098 & 0.935 \\
Social integration in the work & 2.9381 & 2.5854 & 0.370 \\
Constitutionalism in the work & 3.3400 & 3.3220 & 0.903 \\
Social integration in the work & 4.5257 & 4.6390 & 0.133 \\
\hline
\end{tabular}

The results of Table 4 indicate that gender had no meaningful impact on teleworking. In other words, teleworking has maintained good impact on the quality of life for both groups of male and female.

\subsection{The effect of age}

Table 5 demonstrates the results of examining the effects telemarketing on difference groups of people. The results of Table 5 demonstrate that age had no meaningful impact on teleworking. In 
other words, teleworking has maintained good impact on the quality of life on different groups of people.

\section{Table 5}

The results of age on mean difference on telemarketing

\begin{tabular}{lccccc}
\hline Variable & $<25$ & $25-35$ & $35-45$ & $45-55$ & Sig. \\
\hline Adequate and fair compensation & 3.5833 & 3.7628 & 3.569 & 3.6500 & 0.838 \\
Safe and healthy working conditions & 3.7187 & 4.0962 & 4.169 & 3.7625 & 0.404 \\
Opportunity for continued growth and security & 2.3125 & 2.7147 & 2.580 & 2.6500 & 0.479 \\
The social relevance of work life & 3.6875 & 3.9359 & 3.795 & 3.7750 & 0.808 \\
Total life space & 3.6667 & 4.2821 & 4.021 & 4.0167 & 0.076 \\
Social integration in the work & 3.2083 & 2.7885 & 2.838 & 2.6500 & 0.488 \\
Constitutionalism in the work organization & 3.5250 & 3.4385 & 3.135 & 3.2900 & 0.289 \\
Social integration in the work & 4.7250 & 4.6154 & 4.490 & 4.5000 & 0.258 \\
\hline
\end{tabular}

\subsection{The effect of educational background}

Next, we examine the effect of educational background on teleworking. Table 6 demonstrates the results of examining the effects of teleworking on difference groups of people in terms of educational backgrounds.

\section{Table 6}

The results of educational background on telemarketing

\begin{tabular}{lcccc}
\hline Variable & 14 Years & 16 Years & 18 Years & Sig. \\
\hline Adequate and fair compensation & 3.6989 & 3.6373 & 3.8333 & 0.807 \\
Safe and healthy working conditions & 4.3710 & 3.9081 & 3.8333 & 0.084 \\
Opportunity for continued growth and security & 2.8011 & 2.5539 & 2.6806 & 0.269 \\
The social relevance of work life & 3.7204 & 3.9338 & 3.7083 & 0.469 \\
Total life space & 4.2527 & 4.0392 & 4.2083 & 0.354 \\
Social integration in the work & 2.5753 & 2.9265 & 2.7361 & 0.164 \\
Constitutionalism in the work organization & 3.3226 & 3.3235 & 3.4167 & 0.921 \\
Social integration in the work & 4.6194 & 4.5500 & 4.5333 & 0.672 \\
\hline
\end{tabular}

The results of Table 6 demonstrate that educational background had no meaningful effect on teleworking. In other words, teleworking has maintained good impact on the quality of life on different groups of people in terms of various educational backgrounds.

\subsection{The effect of job experience}

Next, we study the impact of job experience on teleworking. Table 7 shows the results of testing the impacts of teleworking on difference groups of people in terms of job experiences.

Table 7

The results of job experience on telemarketing

\begin{tabular}{lcccc}
\hline Variable & $<10$ & $11-20$ & $21-30$ & Sig. \\
\hline Adequate and fair compensation & 3.5937 & 3.8679 & 3.3846 & 0.100 \\
Safe and healthy working conditions & 3.6719 & 4.2453 & 4.0288 & 0.052 \\
Opportunity for continued growth and security & 2.5156 & 2.6365 & 2.9782 & 0.012 \\
The social relevance of work life & 3.7865 & 3.8962 & 3.8333 & 0.859 \\
Total life space & 4.3050 & 4.0385 & 3.456 & 0.020 \\
Social integration in the work & 2.8750 & 2.7484 & 2.8462 & 0.783 \\
Constitutionalism in the work organization & 3.3438 & 3.3887 & 3.2077 & 0.603 \\
Social integration in the work & 4.6250 & 4.5660 & 4.5000 & 0.469 \\
\hline
\end{tabular}

The results of Table 7 show that job experience had no meaningful impact on teleworking. In other words, teleworking has maintained good impact on the quality of life on different groups of people in terms of various job experiences. 


\subsection{The effect of job position}

Finally, we perform t-student test to verify the effect of job position on mean difference of two groups and Table 6 demonstrates the results of our survey.

\section{Table 8}

The results of job position on mean difference on telemarketing

\begin{tabular}{lccc}
\hline Variable & Manager & Regular employee & Sig. \\
\hline Adequate and fair compensation & 3.5937 & 3.7089 & 0.576 \\
Safe and healthy working conditions & 3.8719 & 4.0741 & 0.057 \\
Opportunity for continued growth and & 2.5156 & 2.6857 & 0.254 \\
The social relevance of work life & 3.7865 & 3.8755 & 0.638 \\
Total life space & 3.7742 & 4.2173 & 0.020 \\
Social integration in the work & 2.8750 & 2.7806 & 0.604 \\
Constitutionalism in the work organization & 3.3438 & 3.3291 & 0.926 \\
Social integration in the work & 4.6250 & 4.5443 & 0.317 \\
\hline
\end{tabular}

The results of Table 8 indicate that job position had no meaningful impact on teleworking. In other words, teleworking has maintained good impact on the quality of life for both groups of managers and regular employees.

\section{Conclusion}

In this paper, we have presented an empirical investigation to study the impact of teleworking on quality of life in one of Iranian firms. Using structural equation modeling as well as some basic statistical tests, the study has determined that teleworking influenced on quality of life, significantly. The study has also determined that different personal characteristics such as age, gender, job position and job experience had not impact on quality of life. In other words, no matter whether the employee is female or male, highly educated or not or hold significant amount of job experiences or not, teleworking can make changes on quality of life.

\section{Acknowledgement}

The authors would like to thank the anonymous referees for constructive comments on earlier version of this paper.

\section{References}

Bailey, D. E., \& Kurland, N. B. (2002). A review of telework research: Findings, new directions, and lessons for the study of modern work. Journal of Organizational Behavior, 23(4), 383-400.

Baruch, Y. (2000). Teleworking: benefits and pitfalls as perceived by professionals and managers. New Technology, Work and Employment, 15(1), 34-49.

Fonner, K. L., \& Roloff, M. E. (2010). Why teleworkers are more satisfied with their jobs than are office-based workers: When less contact is beneficial. Journal of Applied Communication Research, 38(4), 336-361.

Illegems, V., Verbeke, A., \& S'Jegers, R. (2001). The organizational context of teleworking implementation. Technological Forecasting and Social Change,68(3), 275-291.

Siha, S. M., \& Monroe, R. W. (2006). Telecommuting's past and future: a literature review and research agenda. Business Process Management Journal, 12(4), 455-482.

Taskin, L. (2010). Introducing telework in a public and bureaucratic environment: a re-regulationist perspective on a non-conventional change. International Journal of Management Concepts and Philosophy, 4(3), 294-310.

Walton, R. E. (1973). Quality of working life-what is it. Sloan Management Review, 15(1), 11-21.

Wellman, B., \& Haythornthwaite, C. (Eds.). (2008). The Internet in everyday life. John Wiley \& Sons. 